\title{
POSSIBLE IMPLICATIONS OF CLIMATE ENGINEERING FOR PEACE AND SECURITY
}

by P. Michael Link, Michael Brzoska, Achim Maas, Götz Neuneck, and Jürgen Scheffran

T

here is a growing discussion about the intentional manipulation and control of the climate system-known as "geoengineering" or "climate engineering." This is in part due to some scientists and political authorities considering geoengineering as a necessary "plan B" option for a "global last resort" to counter catastrophic climate change. While research on climate engineering is already attracting resources and interest, there is a lack of understanding of the potential consequences, in particular for peace and security. A workshop ${ }^{1}$ held at the University of Hamburg, Germany, in the fall of 2011 examined these issues to identify gaps in our understanding of geoengineering and to address emerging questions (the conference program is available at http://clisec.zmaw.de /Conference-program.1929.0.html).

AFFILIATIONS: LINK* AND SCHEFFRAN—Research Group Climate Change and Security, KlimaCampus, Institute of Geography, University of Hamburg, Hamburg, Germany; BRZOSKA AND NeUNECK-Institute for Peace Research and Security Policy, University of Hamburg, Germany; MAAs-Institute for Advanced Sustainability Studies, Potsdam, Germany

*ADDITIONAL AFFILIATION: Research Unit Sustainability and Global Change, Center for Earth System Research and Sustainability, University of Hamburg, Hamburg, Germany CORRESPONDING AUTHOR: P. Michael Link, Research Group Climate Change and Security, KlimaCampus, University of Hamburg, Grindelberg 7 \#2014, D-20144 Hamburg, Germany E-mail: michael.link@zmaw.de

DOI:10.II75/BAMS-D-12-00022.I

In final form 2 June 2012

()ㅣㄹ American Meteorological Society

\section{GEOENGINEERING THE CLIMATE: AN ISSUE FOR} PEACE AND SECURITY STUDIES?

WHAT: An international group of scientists reviewed the potential consequences of climate engineering and provided a first mapping of the problem landscape, identifying knowledge gaps and emerging research questions.

WHEN: 10-II November 2011

WHERE: Hamburg, Germany

In the opening keynote speech, an overview of the different possibilities for geoengineering Earth's climate generally identified two fundamental categories: carbon dioxide $\left(\mathrm{CO}_{2}\right)$ removal (CDR) and solar radiation management (SRM). The overarching goal of all measures is to offset climate change. However, it was argued that geoengineering cannot replace mitigation and adaptation measures when it comes to dealing with climate change-hence, reduction of carbon dioxide emissions remains of utmost importance.

\section{PERSPECTIVES ON GEOENGINEERING.}

The speakers of the introductory session were all very

\footnotetext{
${ }^{1}$ The conference was organized by the Research Group Climate Change and Security (CLISEC) of the KlimaCampus at the University of Hamburg in cooperation with the Institute for Peace Research and Security Policy (IFSH) and the Carl Friedrich von Weizsäcker-Centre for Science and Peace Research (ZNF) of the University of Hamburg, as well as with Adelphi Research in Berlin.
} 
cautious with regard to geoengineering because of the enormous complexity of the subject. To reach sound decisions about geoengineering, it is necessary to adequately consider its historical, economic, ethical, and governance settings.

Historical experiences are important for interdisciplinary communication, innovation, and citizen involvement. Beginning in the 1950s, weather modification projects were conducted and financed by the U.S. military that studied the impact of cloud seeding or nuclear explosions on local weather conditions. The monsoonal cloud seeding during the Vietnam War led to the 1978 Environmental Modification (ENMOD) Convention: an international treaty banning modification of the environment for hostile purposes while allowing its peaceful use. Further research into the historical, legal, and social implications of geoengineering is needed to integrate international, interdisciplinary, and intergenerational issues and perspectives.

While there is certainly an economic perspective to geoengineering, the costs of different measures are difficult to compare. Indirect costs and risk premiums are orders of magnitude higher than actual direct costs. Cheap CDR technologies are as slow as mitigation but have limited potential and considerable uncertainties. The not-yet-demonstrated SRM technologies might be quick fixes and direct costs are conceivably low, but indirect costs and risk premiums are also considerable. Fundamentally, climate engineering is poorly understood and further and early research in the field is critical; whether CDR or SRM technologies then become globally and economically meaningful is still an open question.

The current debate about the need for geoengineering focuses on its governance. Given this critical juncture, one needs to include perception, public reaction, and policy positions when dealing with the policy implications of geoengineering. Currently, many projects, interest groups, and organizations with different views are included in the debate about geoengineering, making it highly complex. Further debate on geoengineering technologies is necessary as they will evolve significantly with further research in the foreseeable future.

There are also ethical dilemmas involved in combating climate change, particularly with SRM. Stratospheric sulfate injection is quick, cheap, and risky, but it constitutes a complex set of options for future actions that very well may lead to ethical dilemmas. We should not take steps on the SRM route if there is a slippery slope toward the dilemmatic worst case and if there are better alternatives available, such as strong mitigation.
GEOENGINEERING-A TAXONOMY. This session addressed various technical approaches to geoengineering. While each of the technologies has its specific risk, cost, and efficiency, the consequences may be similar, in particular within the groups of CDR and SRM technologies.

Dispersion that occurs naturally in volcanic eruptions transports aerosols into the stratosphere and increases the planetary albedo, inducing a cooling effect until removal processes take effect. Injection strategies depend on the lifetimes of different sulfur inputs, particle types and sizes, emission heights, and the distribution of sulfate concentration. Adequate design may allow more selective geoengineering approaches. Side effects of deliberate aerosol injections are possible, however, and include impacts on sky whitening, surface cooling, and vegetation, as well as impacts on the ozone layer, ocean circulation, and marine biogeochemistry.

The sequestration potential of all methods of CDR is likely to be limited to about $1 \mathrm{Gt}$ of carbon per year. Inputs from land and artificial upwelling in the ocean may have possible side effects such as disturbing the Earth's radiation balance, while fertilizing the oceans with iron messes up ecosystems. Whenever artificial ocean upwelling is stopped, mean temperatures soon exceed those of a world without previous geoengineering. When assessing the effectiveness of geoengineering measures, the effects have to be compared to a world with $\mathrm{CO}_{2}$ emissions but without ocean fertilization.

Although afforestation (as well as reforestation, including sustainable forest management strategies) is carbon sequestration, it also affects the solar radiation balance because of the lower albedo of forest cover. A comparison of the sequestration potentials in different countries revealed a distinct geographic heterogeneity. Furthermore, a life cycle assessment of wood products showed that recycling leads to reduced energy consumption. Future research should focus on the rehabilitation of degraded sites by forest plantations, mitigation strategies in forest management, and timber utilization.

While carbon capture and sequestration (CCS) is globally considered a highly relevant technology for climate protection, its $\mathrm{CO}_{2}$ mitigation potential depends on technical, economic, geographic, and temporal factors. Implementation and deployment of CCS are highly complex problems, not only from a technical perspective, but also from economic, logistic, political, and societal perspectives. NonOrganisation for Economic Co-operation and Development (OECD) countries, especially China 
and India, are key actors when it comes to longterm CCS deployment. However, there are barriers for CCS based on $\mathrm{CO}_{2}$ mitigation costs, limited geographic proximity of potential $\mathrm{CO}_{2}$ sources and storages, and the uncertain regulatory framework conditions.

\section{GEOENGINEERING-PEACE AND} SECURITY. This session explored the possible implications of geoengineering for peace and security that have so far received much less attention than the technical aspects of geoengineering.

Among the potential benefits and risks of geoengineering, 25 negative and 9 positive implications were introduced. If geoengineering prevented climate change, then it might indeed prevent future conflict. However, this potential benefit is very likely to be outbalanced by negative effects of geoengineering for different regions and societies. Such differences may give rise to contention and conflict. Furthermore, geoengineering might be misused for military purposes. There are several examples in recent history of new technologies that were used by the military, even if they were originally introduced with only civilian intention.

The unequal distribution of the effects of geoengineering is an important issue. If implemented, geoengineering could sharpen a number of fundamental problems of climate change, such as the degradation of water resources, decline in food production, increased extreme weather events, or mass migration, all of which are potential sources of conflict. Conflicts can arise on many levels because geoengineering will have multiple effects that can reach from the local to the global level. Some are intended-particularly the cooling of the planet-but some are unintentional (e.g., shifts in precipitation patterns, changes in the intensity of weather events, local environmental impacts, etc.). The latter may only become noticeable after some time, making it difficult to establish their links to geoengineering. While more research about the consequences of geoengineering is favorable, more attention should be given to the improvement of anticipatory and adaptive climate policies.

Geoengineering might in principle prevent some of the negative effects of climate change, making us "free" in the sense of removing or at least lessening threats to fundamental freedoms. However, there is a danger that it may have additional unintended side effects. Thus, the uncertainty about the effects of geoengineering on livelihoods makes climate mitigation a more attractive strategy. Furthermore, geoengineering may create problems for democracy, the rule of law, and societal institutions, when it needs to be enforced against popular opposition.

As part of an investigation of the already existing global framework that may be applied to geoengineering, the ENMOD Convention was again mentioned. Geoengineering could have harmful consequences for some states or regions, and therefore it would be considered hostile, even though the underlying intentions were solely peaceful. The ENMOD Convention therefore cannot be directly applied to geoengineering. However, it points to the importance of precautionary measures as those developed in the framework of preventive arms control. It is important to set norms and standards with regard to geoengineering, and to build institutions for the monitoring and verification of lawful behavior and for the exchange of relevant information.

Three plausible scenarios for applying geoengineering techniques in the future were developed in theory within a larger effort to study potential environment-related threats that might occur over a few decades. These scenarios show the variety of possibilities of the development of geoengineering, ranging from joint multilateral efforts to a decentralized distribution of geoengineering technology that can no longer be controlled. Then geoengineering would occur in a trial and error mode with many unintended consequences, becoming a source for widespread international conflict.

\section{GEOENGINEERING-A GLOBAL GOVERNANCE ISSUE? The final session} focused on possible governance arrangements for geoengineering. Particular risk management is necessary not only for geoengineering deployment but also for research, given the possible social, political, economic, and environmental consequences.

Key issues are public perception and framing. In several countries, such as the United Kingdom and the United States, public awareness of geoengineering is growing. However, in most countries, including Germany, there is hardly any public knowledge or awareness. A few nongovernmental organizations (NGOs) have addressed geoengineering but have generally rejected it. Judging from research on other technologies such as CCS, communication that starts early and lasts throughout the entire decisionmaking process is crucial for the public acceptance of decisions.

Regulation of virtually all geoengineering technologies would need to be international if not global, given its transboundary nature. However, no treaty 
exists to deal with geoengineering in a comprehensive manner. From the perspective of customary international law, significant transboundary harm needs to be prohibited and states have to take due regard to territorial integrity of other states when researching or deploying geoengineering-such as informing and consulting potentially affected countries. Additionally, environmental impact assessments need to be carried out in advance. However, based on the existing treaty law as well as customary international law, it can be concluded that any unilateral action would be unlawful.

The notion of unilateral geoengineering is of significant concern beyond the legal realm. Aside from the question of whether a single country could really create a locally favorable climate, the mere risk of unintended side effects may create domestic and international opposition. A key dispute within the discussion was how geoengineering research should be designed and if it can be limited to computer modeling or whether it requires real-world experiments. Given the dangers involved in possible field tests, the precautionary principle may indeed prohibit research in this area, as environmental harm could not be ruled out-yet this would also prevent collecting the scientific evidence to determine the suitability of geoengineering.

Against the background of these issues, there remains a strong need to focus on minimizing impacts on the climate using renewable energies, reforestation, changed agricultural practices, and a strong reduction of deforestation. Geoengineering is not only risky but also difficult to govern. In view of the many major unresolved questions with respect to geoengineering, all countries having adopted the precautionary principle for environmental policy making (such as the European Union) need to currently refrain from adopting any geoengineering measures.

CONCLUSIONS. The workshop highlighted that geoengineering offers substantial chances to address the adverse consequences of climate change. However, geoengineering is highly complex and the interactions and feedback mechanisms of geoengineering measures with the rest of the climate system are not yet fully understood. Thus, more research into the ideas and the development and deployment of geoengineering needs to be conducted. Furthermore, the societal, political, economic, and environmental implications of geoengineering are highly uncertain. Nonetheless, they are potentially significant so they should not be disregarded. In light of these concerns, it should be emphasized that geoengineering is currently not and should not become the only option available to counter global warming. The geoengineering debate needs to be based on an integrated approach to deal with climate change that considers a policy mix including mitigation, adaptation, and geoengineering without merely focusing on one of these areas. 